\title{
Correction to: Swimming Program on Mildly Diabetic Rats in Pregnancy
}

\author{
Nathália C. D. Macedo ${ }^{1}$. Isabela L. lessi ${ }^{1}$ • Franciane Q. Gallego ${ }^{1}$ - Aline O. Netto ${ }^{2}$ Y Yuri K. Sinzato ${ }^{1}$. \\ Gustavo T. Volpato ${ }^{3}$ • Elena Zambrano ${ }^{4}$. Débora C. Damasceno ${ }^{1}$ (I)
}

Published online: 19 February 2021

(C) Society for Reproductive Investigation 2021

\section{Correction to: Reproductive Sciences https://doi.org/10.1007/s43032-021-00462-0}

This article was updated to correct the affiliation numbers in the author display.

Publisher's Note Springer Nature remains neutral with regard to jurisdictional claims in published maps and institutional affiliations.

The online version of the original article can be found at https://doi.org/ $10.1007 / \mathrm{s} 43032-021-00462-0$

\section{Débora C. Damasceno}

debora.damasceno@unesp.br

1 Laboratory of Experimental Research on Gynecology and Obstetrics, Postgraduate Program on Tocogynecology, Botucatu Medical School, São Paulo State University (UNESP), Botucatu, São Paulo State, Brazil

2 Southwest Paulista University Center (Unifsp), Itapetininga, São Paulo State, Brazil

3 Laboratory of System Physiology and Reproductive Toxicology, Institute of Biological and Health Sciences, Federal University of Mato Grosso (UFMT), Barra do Garças, Mato Grosso State, Brazil

4 Departamento de Biología de la Reproducción, Instituto Nacional de Ciencias Médicas y Nutrición Salvador Zubirán, Cuidad de México, México 